II Sección: Sociedad, juventud e inmigración

\title{
Los inmigrantes chinos y sus descendientes, una mirada desde los relatos de vida
}

Susan Chen Mok
Sede del Pacífico
Universidad de Costa Rica, Costa Rica
susan.chen@ucr.ac.cr
https://orcid.org/0000-0002-0572-6850

Recibido: 30 de octubre de 2017

Aceptado: 4 de febrero de 2018

\section{Resumen}

El objetivo de este trabajo es recuperar los relatos de vida de los inmigrantes chinos y/o sus descendientes de la ciudad de Puntarenas del siglo XX para contribuir a la construcción del proceso de la inmigración china en Costa Rica. Este estudio analiza los relatos de vida de dieciocho inmigrantes $\mathrm{y} / \mathrm{o}$ descendientes directos de estos, todos adultos mayores del siglo XX. Se utiliza la técnica de relatos de vida propuesta por Bertaux (2005). Las conclusiones muestran que la comunidad china se ha insertado en la comunidad Puntarenense de manera pacífica y amistosa, aportando sus rasgos culturales y costumbres e integrándose a la vida cotidiana de esta ciudad.

Palabras claves: inmigración china; relatos de vida; cultura china; Comunidad China; Puntarenas

\section{Chinese immigrants and their descendants, a look inside their life stories}

\section{Abstract}

The objetive of this research paper is to recover the life stories of Chinese immigrants and / or their descendants of Puntarenas city in the 20th century to contribute to the construction of the process of Chinese immigration in Costa Rica. This study analizes of the life stories of eighteen immigrants and / or direct descendants of these, all of them senior citizens in the 20th century. The life story technique proposed by Bertaux (2005) is used. The conclusions show that the Chinese community has inserted itself into the community of Puntarenas in a

\section{(c) (i) (2)}

La Revista Estudios es editada por la Universidad de Costa Rica y se distribuye bajo una Licencia Creative Commons Atribución-NoComercial-CompartirIgual 3.0 Costa Rica. Para más información envíe un mensaje a 
peaceful and friendly way, contributing its cultural features and customs and integrating itself into the daily life of this city.

Keywords: Chinese immigration; life stories; Chinese culture; Chinese community; Puntarenas

\section{Introducción}

El interés de recuperar la memoria contenida en las personas adultas mayores que son inmigrantes o descendientes directos de éstos, del siglo $X X$, se debe a que son muy pocos los estudios existentes en este tema que se basan en fuente primaria de información como son los relatos de vida. La mayoría de los estudios están basados en fuente primaria de tipo documental o fuentes secundarias. El uso de los relatos de vida permite obtener información directamente de los participantes en el proceso y ofrece una cantera de información de tipo empírico que no ha sido registrado y que puede perderse debido a la defunción de sus depositarios y a la escasa atención recibida por parte de las instituciones.

De acuerdo a los estudios existentes, los primeros inmigrantes chinos ingresaron a Costa Rica por Puntarenas en el año 1855, lo que permite todavía identificar varios de sus descendientes directos, para que nos relate fragmentos de sus historias de vida. Además, durante el siglo XX continuaron las inmigraciones al país desde China, por lo que es posible identificar algunos de estos inmigrantes directos para conocer su experiencia del proceso y su inserción social a la comunidad puntarenense.

\section{Metodología}

Como se ha mencionado, se utiliza la técnica de relatos de vida, como lo propone Bertaux (2005). Para él, los actores contribuirán no sólo con experiencias diferentes de las relaciones sociales según su posición estructural (y su itinerario pasado), sino también con puntos de vista diferentes (incluso opuestos en cuanto a su carga de evaluación) sobre las mismas realidades sociales (Bertaux, 2005, p.27).

\section{(c) (i) (3) (2)}

La Revista Estudios es editada por la Universidad de Costa Rica y se distribuye bajo una Licencia Creative Commons Atribución-NoComercial-CompartirIgual 3.0 Costa Rica. Para más información envíe un mensaje a 
El relato de vida es un testimonio de la experiencia de vida, pero es un testimonio orientado por la intención de conocer del investigador que lo recoge (Bertaux, 2005, p. 51). En este caso, la intención es reconstruir el proceso de la inmigración china en Puntarenas y su inserción social.

Este mismo autor considera que hay un relato de vida desde el momento en que un sujeto cuenta a otra persona, investigador o no, un episodio cualquiera de su experiencia vivida. Lo que significa que la producción discursiva del sujeto ha adoptado una forma narrativa (Bertaux, 2005, p.36). Además, una entrevista narrativa orientada a la reconstrucción de situaciones contiene necesariamente un buen número de informaciones generalmente exactas basadas en hechos (Bertaux, 2005, p.12).

Utilizamos el relato de vida como función exploratoria y analítica como lo explica Bertaux (2015, p.52), es decir, exploratoria porque nos permite formar una idea general del objeto de estudio y analítica porque nos permite ir viendo el momento en que varios relatos comienzan a llegar a un punto de saturación. El punto de saturación es lo que Bertaux (2005) llama a la repetición de información o modos de ver las cosas con respeto a lo que se está investigando.

Se trata de tener varios relatos de vida de personas que se hallan o se han hallado en situaciones sociales similares, o participando en el mismo mundo social, en este caso que nos interesa, personas que hayan vivido el proceso de la inmigración desde China o son los descendientes directos de éstos, que vivieron o viven en Puntarenas, para sacar provecho de los conocimientos que ellas han adquirido mediante su experiencia directa de ese mundo, proceso o situación.

De acuerdo con Bertaux (2005, p.11), los relatos de vida no excluyen en absoluto a otras fuentes, en este caso, se utiliza otras fuentes secundarias y observación directa por parte del investigador.

Para delimitar la población de inmigrantes y descendientes, se define realizar las entrevistas a personas adultas mayores que sean inmigrantes 0 sus descendientes directos y que vivieron o viven en Puntarenas. Se define como 
Revista Estudios, (36), 2018.

ISSN 1659-3316

Junio 2018-Noviembre 2018

Chen Mok Susan

persona adulta mayor, como la establece la Ley Integral para la Persona Adulta Mayor, Ley No. 7935 de Costa Rica, "toda persona con sesenta y cinco años o más" (Asamblea Legislativa, 1999, p.1).

La inmigración china en Puntarenas ha continuado durante todo el siglo XX y lo que va del siglo $\mathrm{XXI}$, sin embargo, se excluye las inmigraciones más recientes (personas que no entran en la categoría de adulto mayor) debido a que se desea conocer y recuperar los relatos de los adultos mayores por la experiencia contenida en su historia de vida y por el contexto histórico del siglo XX que vivieron.

Se definen las siguientes categorías de análisis: proceso de la inmigración, familia, religión, gastronomía, inserción social, idioma, trabajo, matrimonio, educación, desarraigo.

Se incluyen dentro del texto extracto de los relatos de vida que permiten acercar al lector al contexto de la vivencia que se trata de describir.

En el cuadro siguiente se muestra los datos básicos de los relatores:

Cuadro 1. Información básica de los relatores.

\begin{tabular}{|l|l|l|l|l|}
\hline Nombre & $\begin{array}{l}\text { Edad al } \\
\text { año 2016 }\end{array}$ & Educación & $\begin{array}{l}\text { Lugar de } \\
\text { nacimiento }\end{array}$ & $\begin{array}{l}\text { Residencia } \\
\text { actual }\end{array}$ \\
\hline Jesús Ayí Con & 73 & $\begin{array}{l}\text { Universidad } \\
\text { incompleta }\end{array}$ & Puntarenas & $\begin{array}{l}\text { Uruca, San } \\
\text { José }\end{array}$ \\
\hline Sonia Lo Tsang & 74 & Sexto grado & Cantón, China & Puntarenas \\
\hline $\begin{array}{l}\text { Yolanda Wong } \\
\text { Soto }\end{array}$ & 75 & $\begin{array}{l}\text { Universitaria } \\
\text { completa }\end{array}$ & Puntarenas & Puntarenas \\
\hline $\begin{array}{l}\text { María Cheang } \\
\text { Chan Alan }\end{array}$ & 75 & $\begin{array}{l}\text { Secundaria } \\
\text { incompleta }\end{array}$ & Macao, China & $\begin{array}{l}\text { Tres Ríos, San } \\
\text { José }\end{array}$ \\
\hline $\begin{array}{l}\text { Alfredo } \\
\text { Sánchez }\end{array}$ & $\begin{array}{l}\text { Universitaria } \\
\text { completa }\end{array}$ & San José & $\begin{array}{l}\text { Tres Ríos, San } \\
\text { José }\end{array}$ \\
\hline
\end{tabular}

La Revista Estudios es editada por la Universidad de Costa Rica y se distribuye bajo una Licencia Creative Commons Atribución-NoComercial-CompartirIgual 3.0 Costa Rica. Para más información envíe un mensaje a revistaestudios.eeg@ucr.ac.cr. 
Revista Estudios, (36), 2018.

ISSN 1659-3316

Junio 2018-Noviembre 2018

Chen Mok Susan

\begin{tabular}{|c|c|c|c|c|}
\hline $\begin{array}{ll}\text { Miriam Sánchez } \\
\text { Chan }\end{array}$ & 77 & $\begin{array}{l}\text { Secundaria } \\
\text { completa }\end{array}$ & Puntarenas & San José \\
\hline Jania Chan Li & 79 & $\begin{array}{l}\text { Secundaria } \\
\text { incompleta }\end{array}$ & $\begin{array}{l}\text { Esparza, } \\
\text { Puntarenas }\end{array}$ & $\begin{array}{l}\text { El Roble, } \\
\text { Puntarenas }\end{array}$ \\
\hline $\begin{array}{l}\text { Fernando Wong } \\
\text { Chan }\end{array}$ & 79 & $\begin{array}{l}\text { Universitaria } \\
\text { completa }\end{array}$ & Puntarenas & Puntarenas \\
\hline $\begin{array}{l}\text { Rafael Kun Fai Li } \\
\text { Shi }\end{array}$ & 80 & $\begin{array}{l}\text { Secundaria } \\
\text { incompleta }\end{array}$ & Cantón, China & Puntarenas \\
\hline $\begin{array}{l}\text { Guillermo Apuy } \\
\text { Soto }\end{array}$ & 80 & $\begin{array}{l}\text { Universitaria } \\
\text { incompleta }\end{array}$ & $\begin{array}{l}\text { Pithaya, } \\
\text { Puntarenas }\end{array}$ & Puntarenas \\
\hline Ana Sui Mok & 80 & $\begin{array}{l}\text { Primaria } \\
\text { completa }\end{array}$ & Cantón, China & $\begin{array}{l}\text { Chacarita, } \\
\text { Puntarenas }\end{array}$ \\
\hline $\begin{array}{l}\text { Francisco Chango } \\
\text { Achío }\end{array}$ & 81 & $\begin{array}{l}\text { Primaria } \\
\text { incompleta }\end{array}$ & $\begin{array}{l}\text { Guacimal, } \\
\text { Puntarenas }\end{array}$ & $\begin{array}{l}\text { Barranca, } \\
\text { Puntarenas }\end{array}$ \\
\hline Rogelio Chin Fong & 84 & $\begin{array}{l}\text { Universitaria } \\
\text { incompleta }\end{array}$ & Puntarenas & Pavas, José \\
\hline Carlos Li Chen & 85 & $\begin{array}{l}\text { Secundaria } \\
\text { incompleta }\end{array}$ & $\begin{array}{l}\text { Esparza, } \\
\text { Puntarenas }\end{array}$ & Puntarenas \\
\hline Isidro Con Wong & 85 & $\begin{array}{l}\text { Primaria } \\
\text { incompleta }\end{array}$ & Puntarenas & San José \\
\hline Athala Li Chen & 87 & $\begin{array}{l}\text { Primaria } \\
\text { completa }\end{array}$ & $\begin{array}{l}\text { Bagaces, } \\
\text { Guanacaste }\end{array}$ & Puntarenas \\
\hline Ana Acón León & 92 & $\begin{array}{l}\text { Primaria } \\
\text { incompleta }\end{array}$ & Cantón, China & Puntarenas \\
\hline $\begin{array}{l}\text { Rosario Golfín } \\
\text { Calderón }\end{array}$ & 93 & $\begin{array}{l}\text { Primaria } \\
\text { incompleta }\end{array}$ & Puntarenas & $\begin{array}{l}\text { El Roble, } \\
\text { Puntarenas }\end{array}$ \\
\hline
\end{tabular}

Fuente: elaboración propia con datos del proyecto de investigación (Chen, 2016a).

La Revista Estudios es editada por la Universidad de Costa Rica y se distribuye bajo una Licencia Creative Commons Atribución-NoComercial-CompartirIgual 3.0 Costa Rica. Para más información envíe un mensaje a revistaestudios.eeg@ucr.ac.cr. 
Revista Estudios, (36), 2018.

Junio 2018-Noviembre 2018

ISSN 1659-3316

Chen Mok Susan

Proceso de la inmigración

El grupo de adultos mayores cuatro mujeres nacieron en Cantón China y vinieron

a Costa Rica, casada o a casarse (Lo Tsan, 2016), (Acón León, 2016), (Cheang Chan, 2016), (Sui Mok, 2016). El único varón que nació en China, inmigró a Costa Rica siendo un bebé de meses (Li Shi, 2016). Todos los demás nacieron en Costa Rica, principalmente en comunidades de la provincia de Puntarenas y sus alrededores.

La mayoría de los descendientes cuentan que sus padres vinieron de China por razones de búsqueda de una mejor vida, huyendo de la situación política, social y económica de su país. Igualmente, las mujeres que nacieron en China decidieron venirse a Costa Rica por las mismas razones.

Los descendientes directos de inmigrantes indican que sus padres llegaron al país porque ya había algún familiar o amigo que los ayudaba, podía ser el padre, suegro, el tío, hermano, abuelo o amigo. El viaje lo hicieron en barco y/o avión.

Mi papá vino uh hace tiempo, nosotros nacimos en 1936, vino 10 años antes luego se volvió otra vez para la China, se vino otra vez solo, entonces mandó a traer a mi mamá de la China se venía en barco, 5 meses en barco. (Apuy Soto, 2016, p. 5).

Mi abuelo fue el primero que vino de China, él se llamaba Gil Con, mi papá vino con él en el $48 \mathrm{creo}$, cuarenta y resto. Mi papá nació en China y vino aquí traído por el abuelo. Fue mi abuelo materno que lo trajo, o sea el suegro de papá fue el que lo trajo a él. (Ayí Con, 2016, p. 1).

Mi papá se vino primero soltero, se vino en barco en ese tiempo tenían que venirse en barco, vino porque en ese tiempo mi tío el hermano mayor de él ya vivía en Costa Rica... (Chin Fong, 2016, p. 1)

En el caso de las mujeres, dos de ellas establecieron relación con su pareja en China (Acón León, 2016), (Cheang Chan, 2016). Se conocían y mantenían relación de noviazgo, el varón decide ir a Costa Rica por las expectativas de mejor vida y por la presencia de familiares o amigos que les permitían viajar a Costa Rica. El varón luego de establecerse en el nuevo país, envía por ella y contraen

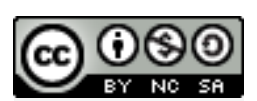

La Revista Estudios es editada por la Universidad de Costa Rica y se distribuye bajo una Licencia Creative Commons Atribución-NoComercial-CompartirIgual 3.0 Costa Rica. Para más información envíe un mensaje a revistaestudios.eeg@ucr.ac.cr. 
matrimonio en Costa Rica, o regresa a la China para casarse y traerse a su esposa.

Una de ellas conoció a su pareja porque éste fue a la China a buscar esposa y se lo presentaron, establecieron relación de noviazgo en China y pocos meses después contrajeron matrimonio en China (Lo Tsan, 2016). Una vez casados, la mujer viaja con su marido a Costa Rica, dejando a toda su familia en China.

Otra de ellas viaja a Costa Rica porque recibió solicitud de matrimonio a través de conocido suyo en la China (Sui Mok, 2016). Le informaron que un joven en Costa Rica deseaba contraer matrimonio con ella. No se conocían, pero eran del mismo barrio. El joven pretendiente fue compañero de estudios de uno de sus hermanos mayores. La joven tomó la decisión de venir a Costa Rica, por la oportunidad de una mejor vida, pues en China pasaban mucha miseria y necesidades, había mucha pobreza.

... allá en la China me dijeron que estaba Juan acá en Costa Rica, que si me acordaba de él, que fue compañero del colegio de mi hermano. Mi hermano además era muy amigo del hermano de Juan, llamado Chong Send Hau, que era vecino de donde yo trabajaba. En ese tiempo yo ya estaba en Macau, trabajando en una frutería. Ante la propuesta de salir de allá y venirme a Puntarenas yo acepté, porque allá se trabajaba muy duro y no se salía de la pobreza. (Sui Mok, 2016, p. 1)

\section{Educación, trabajo y ocio}

Varios de los descendientes cuentan que sus padres los enviaron a China con sus abuelos o tíos para que estudiaran en China y aprendieran el idioma y su cultura (Li Shi, 2016), (Li Cheng, 2016), (Wong Chan, 2016), (Apuy Soto, 2016).

... me mandaron para China, allá estuve 3 años, no había aprendido chino y el español se me estaba olvidando, es que cuando regresé aquí porque estaban los comunistas ya por llegar allá al pueblo de nosotros, entonces me mandaron de vuelta para acá, aquí llegué mitad hablando chino y mitad español... (Li Shi, 2016, p. 1)

... nos mandaron a estudiar a China con otro paisano hermano de Salvador Wong. Tenía 11 años, y en ese tiempo él llevaba como 11 güilas, pero de diferentes familias. De mis hermanos solo Yo y Juan y Miguel, los 3 nada más. (Apuy Soto, 2016, p. 1)

\section{(c) (i) (2)}

La Revista Estudios es editada por la Universidad de Costa Rica y se distribuye bajo una Licencia Creative Commons Atribución-NoComercial-Compartirlgual 3.0 Costa Rica. Para más información envíe un mensaje a revistaestudios.eeg@ucr.ac.cr. 
Revista Estudios, (36), 2018.

ISSN 1659-3316

Junio 2018-Noviembre 2018

Chen Mok Susan

Generalmente esto ocurría con los hijos varones. Pero todos al final se devolvieron por la crisis política que se estaba viviendo en China con la entrada del comunismo a ese país (entre los años 50 y 60).

Todos estudiaron, algunos lograron niveles universitarios (Ayí Con, 2016), (Wong Soto, 2016), (Alán Sánchez, 2016), (Wong Chan, 2016), (Apuy Soto, 2016), (Chin Fong, 2016) pero la mayoría no terminaron la secundaria, debido a que se dedicaron al comercio principalmente.

Algunos heredaron el negocio de sus padres (Chango Achio, 2016), (Li Shi, 2016), (Con Wong, 2016).

En el caso de las señoras inmigrantes, se integraron al trabajo de sus maridos, los cuales tenían negocio en el comercio de Puntarenas: abastecedor, restaurante, tienda, soda, pulpería, almacén.

... yo me quedé con el negocio... El negocio lo teníamos como... como comisariato que llamaban antes, teníamos tienda, zapatería, tenía hasta botiquín, vendíamos cocinas y cosas así y después todo lo que era todo abarrotes pedíamos abarrotes y un poco de bar también. (Chango Achio, 2016, p. 2)

... al principio que llegué aquí no metí negocio todavía porque estaba cuidando los güilas ya después de varios años, entonces si me metí más de lleno al negocio, en aquellos tiempos ya me aprendí un poquito más el español. (Lo Tsan, 2016, p. 3)

Las mujeres descendientes ayudaban a sus padres en los oficios domésticos, en sus pequeños negocios, a cuidar de sus hermanos o se dedicaban completamente a estudiar en alguno de los casos. Si se casaba se integraba a la familia del marido y se encargaba de los oficios domésticos del nuevo hogar así como a ayudar en el negocio de su marido (Wong Soto, 2016), (Li Chen, 2016), (Chan Golfín, 2016), (Sánchez Chan, 2016).

En los quehaceres del hogar contaban con empleadas que les ayudaban.

Algunos de los que estudiaron se integraron al trabajo en las empresas públicas y/o privadas de la provincia o en la capital: aduana (Wong Chan, 2016), IAFA (Wong Soto, 2016), Banco de Costa Rica (Chin Fong, 2016). Uno de ellos llegó a

La Revista Estudios es editada por la Universidad de Costa Rica y se distribuye bajo una Licencia Creative Commons Atribución-NoComercial-Compartirlgual 3.0 Costa Rica. Para más información envíe un mensaje a revistaestudios.eeg@ucr.ac.cr. 
Revista Estudios, (36), 2018.

destacarse como artista pintor de origen chino reconocido de Costa Rica (Con Wong, 2016).

Trabajé en el IAFA 16 años. Me pensioné y me vine para acá (a Puntarenas) otra vez. Me pensioné hace 20 años!! (Wong Soto, 2016, p. 3)

Yo me vine (a San José) porque ya empecé a pintar... Pinto desde pequeño. Toda la vida! (Con Wong, 2016, pp. 7, 8)

Sobre sus padres, la mayoría cuentan que tenían negocios dedicados al comercio en Puntarenas, principalmente almacenes, tiendas y pulperías. Uno informa que su padre tenía fincas con ganado, eran agricultores y también se dedicaron al comercio (Con Wong, 2016). Uno de ellos indica que su padre tenía negocios (uno de ellos es de fábrica de uniformes, ropa y de puros) en San José, principalmente, pero también tenía una fábrica de jabones en Puntarenas y en San José (Alán Sánchez, 2016). Estos casos son ejemplos de que los inmigrantes también se dedicaron a la industria, agricultura y ganadería.

... mi abuelo Antonio, le decía que tenía una fábrica de puros, posteriormente se dedicó a la jabonería algo muy inusual del siglo verdad!, tuvo una jabonería en Puntarenas cerca del antiguo hospital San Rafael, no recuerdo cómo se llamaba la jabonería esa la administraba mi papá... (Alán Sánchez, 2016, p. 2).

Mi bisabuelo Jacobo Sánchez... él yo recuerdo cuando iba pequeño, yo a pasar vacaciones allá, que se distribuía mucha mercadería, abarrotes, era los representantes de la Fábrica Nacional de Licores y de una compañía de cigarrillos no sé si era Mendiola y abarrotes en cantidades, es decir mi bisabuelo era poderoso, era dueño también del teatro Sun Yat Sen. (Alán Sánchez, 2016, p.3).

Todos cuentan que sus padres trabajaban mucho, casi no tenían días libres para la recreación. Si lo tenían eran muy pocos, por lo tanto, sus padres trabajaban mientras ellos jugaban mucho con sus compañeros y amigos, algunos ayudaban a sus padres en el negocio cuando tenía edad para hacerlo o cuando lo requerían.

Mis papás tenían una cantina pulpería, uno les ayudaba. (Li Chen, 2016, p. 1)

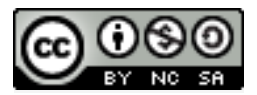

La Revista Estudios es editada por la Universidad de Costa Rica y se distribuye bajo una Licencia Creative Commons Atribución-NoComercial-CompartirIgual 3.0 Costa Rica. Para más información envíe un mensaje a revistaestudios.eeg@ucr.ac.cr. 
Recuerdan algunos paseos al río, o a visitar a otras familias en los alrededores de la misma comunidad porteña, o ir al cine, al parque o la playa.

... muchas veces fuimos a la finca, y a jocotear íbamos, una vez fuimos a Limón me parece! Otra vez fuimos a San José a jugar! Yo creo que fútbol o no sé... La finca quedaba en Tortugal en la entrada para ir a Manzanillo, uh todo el mundo iba con sacos y bolsas para agarrar jocotes. También íbamos al río, creo que era el río Lagarto. (Li Chen, 2016, p. 1)

El trabajo duro de los primeros años hacía que la mayoría de las familias chinas no tuvieran tiempo para el ocio, los padres trabajaban de lunes a domingo, desde tempranas horas hasta tarde en la noche. Algunos cerraban el domingo más temprano lo que les permitían compartir con otros colegas juego de mesa como "machok" en la casa de alguno de ellos o en el Club Chino.

También manifiestan que en aquellos tiempos había muchos turistas que iban a Puntarenas en tren y se quedaba por varias noches, además el movimiento de cabotaje generaba un flujo de personas en la ciudad de Puntarenas que permitían mantener todos los pequeños negocios del Puerto. Comparan con la época actual, indicando que antes era más tranquilo, el comercio era floreciente a diferencia de la actualidad donde las ventas han disminuido debido al auge de otros destinos turísticos y las mejoras de las vías de comunicación que permiten que el turista regrese el mismo día.

En aquellos tiempos Puntarenas es muy bueno, porque llega mucha gente de toda la costa entonces viene aquí en los muellecito aquí ahí dejan la lancha en la mañana y gente trae arroz, trae frijoles, gallina, todo llegaba a vender después llega aquí y le compra mercadería y se va, ve aquí antes mucho movimiento. Ya no! (Lo Tsan, 2016, p. 4).

„,, siempre hay turistas, en aquello tiempo también en verano, llegaban en tren, un montón turistas llega ahí. Antes hay más turistas, antes porque está más concentrado solamente en Puntarenas, la gente solo viene a Puntarenas porque no hay otro lugar... (Lo Tsan, 2016, p. 4)

\section{(2) $(100$}

La Revista Estudios es editada por la Universidad de Costa Rica y se distribuye bajo una Licencia Creative Commons Atribución-NoComercial-CompartirIgual 3.0 Costa Rica. Para más información envíe un mensaje a revistaestudios.eeg@ucr.ac.cr. 
Revista Estudios, (36), 2018.

ISSN 1659-3316

Junio 2018-Noviembre 2018

Chen Mok Susan

\section{Matrimonio, familia e inserción social}

Los inmigrantes, así como sus descendientes han contraído matrimonio ya sea con inmigrantes, descendientes de inmigrantes o nativos o nativas costarricenses. Varios descienden de un padre chino y una madre costarricense (Wong Soto, 2016), (Chan Golfín, 2016).

$Y$ varios de los relatores han contraído matrimonio con nativos costarricenses (Chan Li, 2016), (Alán Sánchez, 2016), (Chin Fong, 2016).

Las mujeres inmigrantes contrajeron matrimonio en edad considerada joven (promedio de edad 23 años) y llegaron al país para formar familia con su marido.

La mayoría de los relatores contrajeron matrimonio, pues era importante la formación de una familia. Si no conseguían una esposa en Costa Rica, iban hasta China para buscar y traer una, o la mandaban a traer y contraían matrimonio en Costa Rica. Esto ocurría con los inmigrantes propiamente. En el caso de los descendientes de chinos varones, ya esto dejó de ser costumbre debido a que nacieron y crecieron en el ambiente costarricense, aunque algunos de los descendientes fueron a China a buscar esposa, pues sus padres preferían que se casaran con chinas, no era una exigencia que todos debieron cumplir.

\footnotetext{
Yo me casé con una chinita. La fui a traer a Hong Kong ella es de Hong Kong, la conocí allá y nos casamos, era costumbre de los paisanos. Eran muy estrictos en ese tiempo verdad porque siempre buscaban la misma gente, la misma cultura... no precisamente del mismo cantón, pero sí que sean chinos, se suponía que las costumbres eran más parecidas que la gente occidental. (Ayí Con, 2016, p. 3)
}

En el caso de ser descendiente de chinos mujer, los padres trataban de buscar un marido chino y casarla joven. Sin embargo, no era una exigencia obligatoria.

La mayoría de las parejas se mantienen unidas en el vínculo matrimonial hasta que la muerte los separa. Sin embargo, hay algunas pocas excepciones, donde encontramos parejas separadas o divorciadas (Chin Fong, 2016), (Li Shi, 2016). Esto ocurre principalmente con algunos casos de los descendientes directos.

\section{(c) (i) (2) (2)}

La Revista Estudios es editada por la Universidad de Costa Rica y se distribuye bajo una Licencia Creative Commons Atribución-NoComercial-CompartirIgual 3.0 Costa Rica. Para más información envíe un mensaje a revistaestudios.eeg@ucr.ac.cr. 
Un rasgo cultural que sobresale en todos los relatos es que en las familias chinas se respeta a las personas mayores, y la formación de la familia es muy importante. También era posible la convivencia de varias familias en un mismo hogar.

Alguno de los hijos se hacen cargo de las personas mayores y éstas viven con la familia de su hijo o hija o muy cerca de ella, permitiendo de esta manera el cuido de los adultos mayores por parte de sus propios hijos.

Todos los matrimonios tienen el objetivo de formar familia y tener descendientes, así vemos que todas las parejas tuvieron sus hijos.

...hay más respeto por la gente mayor, en la China antes no sé ahora, el hermano mayor siempre se hacía cargo de los padres, una vez casado ya los padres se quedaban con el hermano mayor, con su nuera y con sus...Y si se podía vivían en una misma casa, como nosotros, nosotros vivíamos en una misma casa, todos vivíamos en una misma casa, una casa grande que era de alto, el alto era donde vivíamos nosotros y abajo estaba el negocio de papá verdad, y habían muchos cuartos, habían 2 familias, y después vinieron 3 familias que vivíamos ahí en la misma casa... (Sánchez Chan, 2016, p.5).

En cuanto a la integración a la comunicad, la mayoría coincidieron en que no tuvieron problemas para relacionarse con los vecinos de su comunidad, algunos manifiestan haber recibido algún tipo de agresión verbal mínimo (insultos o burlas), pero que ellos no les daban importancia, lo que les permitía adaptarse e integrarse con facilidad a la comunidad puntarenense. Sólo un caso informó que el hostigamiento y la agresión que sufrieron era intolerable y esto fue la motivación para superarse en este país (Acón León, 2016).

En la escuela nos molestaban, nos decía "chinos majá come pan y no pagá o no me da!" Pero mamá decía no les haga caso, entonces nosotros fuimos aprendiendo a no hacerles caso y siempre decían alguna cosilla pero nosotros ya no les dábamos caso... (Wong Soto, 2016, p. 3)

\section{(c) (i) (2)}

La Revista Estudios es editada por la Universidad de Costa Rica y se distribuye bajo una Licencia Creative Commons Atribución-NoComercial-CompartirIgual 3.0 Costa Rica. Para más información envíe un mensaje a revistaestudios.eeg@ucr.ac.cr. 
Revista Estudios, (36), 2018.

ISSN 1659-3316

Junio 2018-Noviembre 2018

Chen Mok Susan

Por otro lado, otro medio de integración fue la formación de una sociedad. Los registros muestran que, en el caso de Puntarenas, la fundación de la colonia china les permitió subsistir como grupo en el nuevo entorno. El nuevo inmigrante recibía ayuda de la asociación permitiéndole asentarse e independizarse.

...cuando venían paisanos de China, venían con una mano adelante y otra atrás, entonces la Colonia acá se reunían, juntaban dinero y se lo daban a esa persona para que hicieran su negocio verdad, pero no regalado verdad, era un préstamo (Sánchez Chan, 2016, p.5)

La Asociación China Puntarenense (nombre jurídico actual) o Club Chino, fue fundada en 1909 por José Chen Apuy y otros miembros destacados de la comunidad china de Puntarenas. La figura 1 muestra la placa que se encuentra en el Club Chino con los nombres de los primeros fundadores de la asociación. El Club Chino originalmente fue bautizado como Wasion que significa "Club de Comerciantes del Celeste Imperio" (Acón, 2016). El edificio que aparece en la figura 2 fue el edificio antiguo del club, el cual fue demolido por los años 1950 para dar paso a un edificio de cemento de dos plantas. En el segundo piso se ubica la actual sede de la Asociación China Puntarenense, y en el primer piso son establecimientos comerciales.

En la entrada del edificio aparece, en dos tablas rojas con letras chinas negras, un mensaje que dice: "Aunque soy extranjero en un país extraño, me siento como en casa" y "Reunido en este club junto con mis paisanos, me entretengo en familia" (Acón, 2016). Esto muestra cómo el Club Chino era un espacio para sentirse en casa y en familia.

\section{(c) (7) (-)}

La Revista Estudios es editada por la Universidad de Costa Rica y se distribuye bajo una Licencia Creative Commons Atribución-NoComercial-CompartirIgual 3.0 Costa Rica. Para más información envíe un mensaje a revistaestudios.eeg@ucr.ac.cr. 


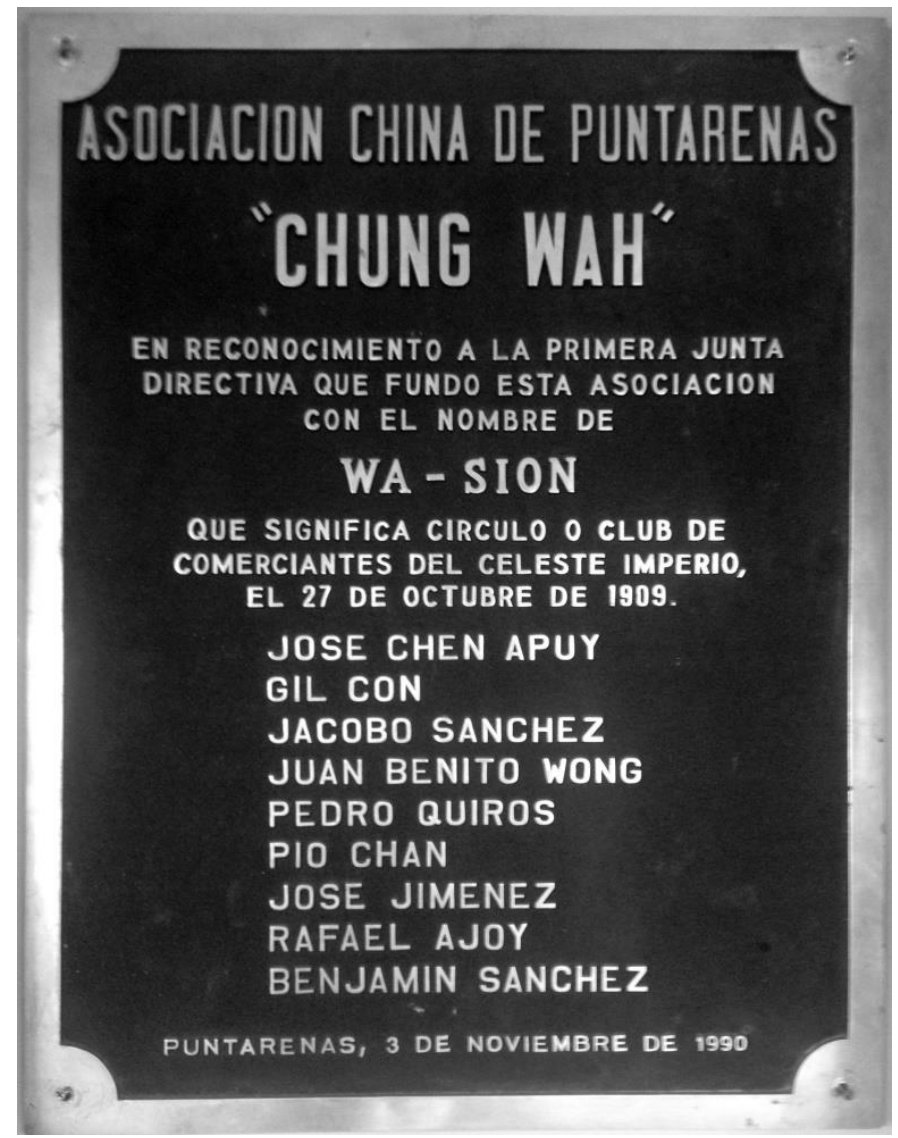

Figura 2. Placa con los nombres de la Primera Junta Directiva de la Asociación

China de Puntarenas. Fuente: (Chen, Base de Datos Fotográfica Proyecto Recuperación de la Memoria Fotográfica y Relatos de Vida de los Inmigrantes Chinos y descendientes de Puntarenas: Siglo XX. UCR, 2016b)

\section{(1) (1) 80}

La Revista Estudios es editada por la Universidad de Costa Rica y se distribuye bajo una Licencia Creative Commons Atribución-NoComercial-Compartirlgual 3.0 Costa Rica. Para más información envíe un mensaje a revistaestudios.eeg@ucr.ac.cr. 


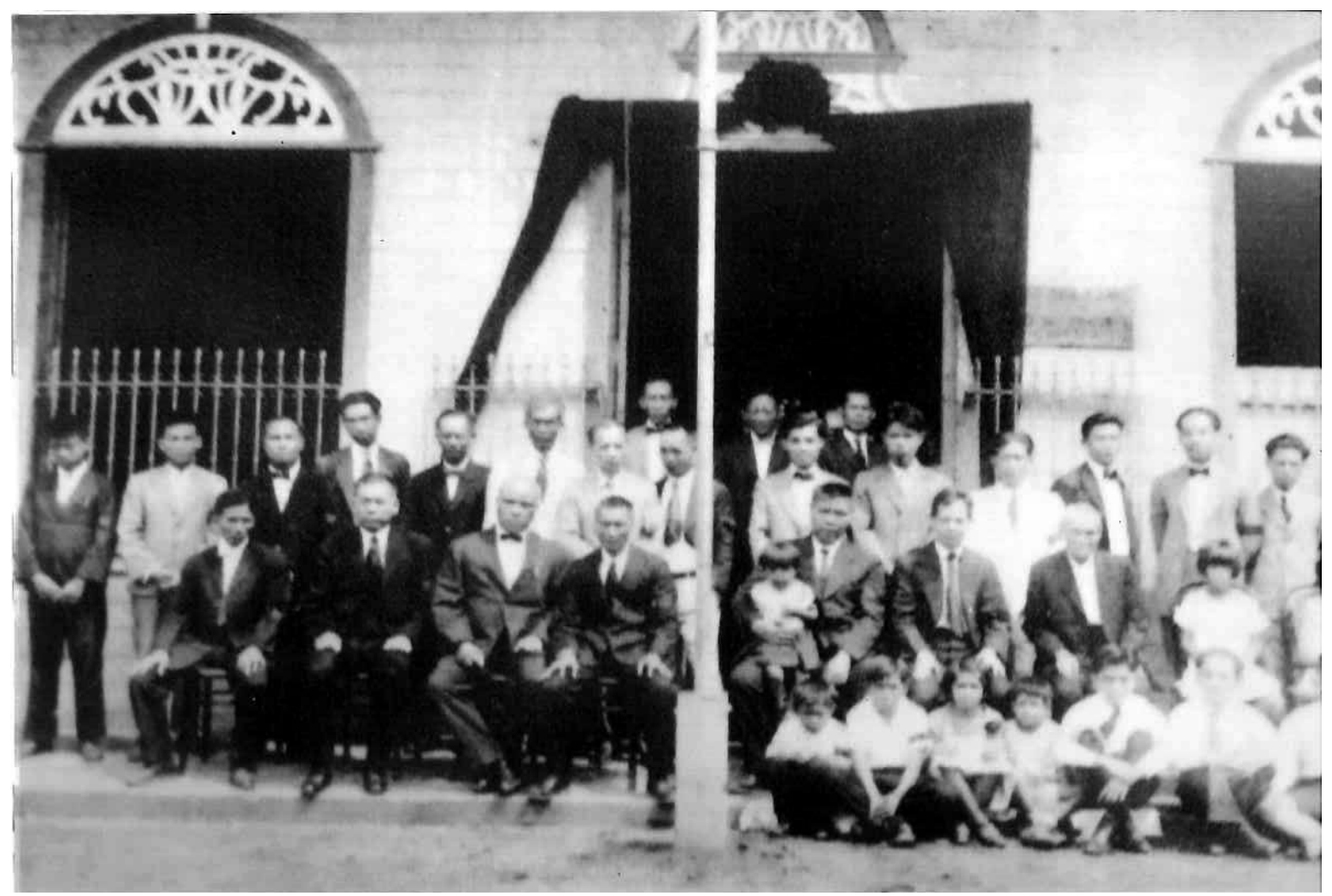

Figura 2. Miembros del capítulo de Puntarenas del Partido Nacionalista o Kuomintang tomada en las afueras del Club Chino en marzo de 1925. Fuente: (Chen, Base de Datos Fotográfica Proyecto Recuperación de la Memoria Fotográfica y Relatos de Vida de los Inmigrantes Chinos y descendientes de Puntarenas: Siglo XX. UCR, 2016b)

Todos los relatores manifiestan que participan o participaban de las actividades de la Club Chino de Puntarenas, tal vez ahora no tanto debido a la edad que tienen, pero cuando eran jóvenes tenían hasta equipos deportivos como tenis de mesa, futbol, baloncesto entre otros.

...en el Club Chino, el nuestro, habían muchas actividades, estaba el ping pong, jugábamos ajedrez, habían juegos de mesa, el limbo todo eso, y hacíamos bailes de vez en cuando... (Sánchez Chan, 2016, p.4)

\section{(c) $10(0$}

La Revista Estudios es editada por la Universidad de Costa Rica y se distribuye bajo una Licencia Creative Commons Atribución-NoComercial-Compartirlgual 3.0 Costa Rica. Para más información envíe un mensaje a revistaestudios.eeg@ucr.ac.cr. 
Revista Estudios, (36), 2018.

ISSN 1659-3316

Junio 2018-Noviembre 2018

Chen Mok Susan

Por medio de la Asociación China tratan de mantener algunas costumbres, aunque la mayoría no recuerdan fechas de celebraciones. La más recordada es la del doble diez, celebración que realizaban el 10 de octubre por la Independencia de la República de Taiwán y que en la actualidad se modificó al 1 de octubre como el día de la Cultura China, después del establecimiento de la relación de Costa Rica con la República Popular China.

Otra celebración que también menciona es la del Año Nuevo Chino. Por supuesto, celebran todas las fechas nacionales, como el día del padre y de la madre, con actividades de integración de los miembros de la colonia y participan de las festividades cívicas y las fiestas de la Virgen del Mar. Los relatores recuerdan que la Colonia China siempre participaba adornando una embarcación para el desfile de lanchas en las fiestas de la Virgen del Mar, que se celebra alrededor del 15 de julio de todos los años.

Mi papá formó parte del Club Chino, ahí todos los domingos iba ahí por eso es que a mí me llevaba y entonces yo practicaba chino, chiquitillo y antes la Colonia China participaban mucho el día por ejemplo de la Virgen del Mar, habían lanchas ahora casi no hay, pero habían lanchas que tenían un toldo entonces había competencia de adornarlas, la Colonia participaba con una lancha, entonces hacían como una carroza arriba y participaban en Puntarenas verdad, ellos participaron. (Chin Fong, 2016, p.3)

La participación de la Colonia China en actividades de la comunidad ha variado conforme ha transcurrido el tiempo, cambiado la Junta Directiva y variado la conformación de los socios. Sin embargo, se mantienen siempre vínculos estrechos con las principales autoridades locales y siempre su aporte al desarrollo económico y cultural de la comunidad es importante.

\section{(C) $(00$}

La Revista Estudios es editada por la Universidad de Costa Rica y se distribuye bajo una Licencia Creative Commons Atribución-NoComercial-CompartirIgual 3.0 Costa Rica. Para más información envíe un mensaje a 
Revista Estudios, (36), 2018.

ISSN 1659-3316

Junio 2018-Noviembre 2018

Chen Mok Susan

\section{Religión, idioma y gastronomía}

La mayoría de los relatores manifiestan ser católicos, aunque algunos no lo practican. Esto es debido a que la mayoría estudiaron en el sistema de educación pública de Puntarenas, donde la religión oficial es la católica. Algunos indicaron que sus padres no profesaban religión alguna, pero como los padrinos, amigos, o parientes eran costarricenses, fueron entonces bautizados. Algunos otros son ateos.

Mi papá que yo sepa no practicaba ninguna religión, mi mamá era católica porque siempre nos mandaba a misa los domingos, y nos mandaba a la cómo es que se llama? que antes daban clases ahí de catecismo entonces nos mandaba a catecismo y a la iglesia los domingos, pero ella no practicaba. (Chin Fong, 2016, p.6).

Papá y mamá no practicaron ninguna religión, como le digo ellos solo se dedicaban al negocio y no tenían tiempo, lo único sí fue que nos bautizaron, eso sí. Pero nunca iban a la iglesia, nos bautizaron porque digamos los padrinos eran de aquí (Wong Chan, 2016, p.5).

En cuanto al idioma, los inmigrantes propiamente saben y practican el idioma, pero la mayoría de los descendientes han perdido el idioma.

El trabajo duro hacía que fuera difícil que los padres se dedicaran exclusivamente a la crianza de sus hijos, por lo que tenían empleadas que les ayudaba en los quehaceres domésticos y el cuido de sus niños pequeños. Esto derivó en la pérdida del idioma en sus descendientes. Algunos tuvieron la dicha de que fueron criados por sus propios padres, abuelos o tías en la infancia, lo que les permitió aprender el idioma cantonés principalmente o Samgión en algunos casos, pues todos los inmigrantes chinos provenían de Cantón, China o Macao.

Mi papá y mi mamá no hablaban español cuando vino y mi papá era chino también entonces en la casa más que nada se hablaba chino cuando yo nací entonces ahí fui viendo y aprendiendo chino. (Chin Fong, 2016, p. 2)

\section{(c) (i) (2)}

La Revista Estudios es editada por la Universidad de Costa Rica y se distribuye bajo una Licencia Creative Commons Atribución-NoComercial-CompartirIgual 3.0 Costa Rica. Para más información envíe un mensaje a revistaestudios.eeg@ucr.ac.cr. 
Revista Estudios, (36), 2018.

Junio 2018-Noviembre 2018

ISSN 1659-3316

Chen Mok Susan

Algunos descendientes aprendieron el idioma porque los enviaron a estudiar a la China en su niñez o juventud, en donde eran cuidados ya sea por sus abuelos o por tíos que se encontraban en ese país. Sin embargo, algunos de los que hablaban chino en su niñez, lo perdieron al ingresar a la edad escolar pues preferían hablar en español en vez del chino.

Son pocos los casos de descendientes que pueden todavía comunicarse en el idioma cantonés (Sánchez Chan, 2016), (Apuy Soto, 2016), (Ayí Con, 2016), (Chin Fong, 2016). Varios de ellos olvidaron el idioma chino por no practicarlo.

Todos han combinado en su gastronomía platillos chinos y costarricenses. También han mezclado ingredientes de ambos produciendo una gastronomía sincrética. Utilizan para sazonar ingredientes como la salsa china o la de ostión. Comen pinto y casados (platillo típico costarricense) así como platillos chinos cuando tienen oportunidad de hacerlo, tales como pescado o costillas al vapor, vegetales chinos salteados y empanadas y otros bocadillos al vapor.

...mi mamá hacía todo "Chi yok pen", huevo al vapor, y hacía "lo pak kou” y "jacau" y todas esas cosas para comer en la casa. (Chin Fong, 2016, p.3).

La familia comía comida china: pescado al vapor, pescado salado, mostaza china, cerdo molido al vapor, trozos de pollo con hongos al vapor, todo siempre acompañado de arroz blanco sin sal ni aceite. Siempre había alguna sopa (de pescado, de semillas, de algas, de verduras, etc.). Se tenía siempre un pichel de té chino a temperatura ambiente. Cuando se tenía sed se tomaba té. (Sui Mok, 2016, p.3).

En la actualidad, es posible conseguir en la capital, productos alimenticios importados de china, productos con los cuales se preparan los platillos chinos. En Puntarenas el acceso a ellos es todavía limitado, sólo es posible conseguirlos si se compran en la capital o en algún establecimiento de algún inmigrante chino que los venda. Esta dificultad no limita a que las familias puedan preparar sus alimentos al estilo chino.

\section{(c) (i) (2)}

La Revista Estudios es editada por la Universidad de Costa Rica y se distribuye bajo una Licencia Creative Commons Atribución-NoComercial-CompartirIgual 3.0 Costa Rica. Para más información envíe un mensaje a revistaestudios.eeg@ucr.ac.cr. 
En la mayoría de las familias, es la esposa la que se encarga de la cocina y alimentación de la familia. La hora de la comida se toma en familia, a menos que la situación de trabajo o estudio lo hiciera difícil. En algunos casos, es el hombre el que cocina, principalmente los que tenían comercio con muchos empleados (los cuales eran también chinos). En estos casos, ya sea que el esposo cocinara 0 algunos de los empleados chinos (Wong Chan, 2016).

Mamá aprendió a cocinar chino! Mi papá le enseñó, papá cocinaba solo los domingos porque el negocio no se lo permitía, entonces los domingos papá cocinaba y le enseñaba de una vez a mamá, entonces mamá fue aprendiendo. (Wong Soto, 2016, p.2).

En mi casa mi señora cocinaba, pero también la tía de ella que ha estado con nosotros, ella cocinaba, era una persona muy mayor también. (Ayí Con, 2016, p.4).

Cuando mi mamá se hizo cargo ya de la pulpería ella siempre cocinaba o alguno de los hermanos o alguien. Normalmente comíamos todos en la mesa, solo cuando uno trabajaba verdad ya no podía estar, pero normalmente sí. (Chin Fong, 2016, p.4).

...yo lo que más me recuerdo sobre todo cuando estaba mi papá que ya llegaba en la tarde a cocinar, esa costumbre que tenía de sentarnos juntos en la mesa a comer todos eso sí y hasta el momento yo a mis hijos les he inculcado eso. (Chan Li, 2016, p.4).

... mi papá era el que cocinaba, él le gustaba cocinar cosas chinas, entonces mi mamá lo dejaba, entonces ella atendía el negocio ajá, y había una empleaba que era que lavaba y hacía las cosas, mi mamá solo nos atendía el negocio y nos cuidaba a nosotros. (Golfín Calderón, 2016, p.2).

\section{Desarraigo}

Los inmigrantes propiamente manifestaron que al principio querían devolverse, pero al ser tan difícil, costoso y distante el regreso a la China, además de que vieron buena oportunidad de trabajo y mejor vida, terminaron acostumbrándose a la vida en Puntarenas.

... cuando llegó a Puntarenas (se refiere a su esposo), se quiso devolver, porque en ese tiempo Puntarenas era de calles de arena, no había corriente, se cocinaba a leña, estaba más retrasada que de donde venía. Se propuso que trabajaría duro para ahorrar, saldar la deuda con la tía y devolverse. Calculaba que en unos diez años saldaría la deuda. (Sui Mok, 2016, p. 1)

\section{(C) $\odot \odot$}

La Revista Estudios es editada por la Universidad de Costa Rica y se distribuye bajo una Licencia Creative Commons Atribución-NoComercial-CompartirIgual 3.0 Costa Rica. Para más información envíe un mensaje a revistaestudios.eeg@ucr.ac.cr. 
La ayuda de los vecinos fue importante para su integración a la comunidad porteña, para aprender el idioma y criar a sus hijos, así como para surgir con su pequeño negocio.

Todo mundo más bien muy bueno conmigo, muy cariñoso y veces yo no hablo bien español, y la en negocio a ellos corregía, corregía a mí, aja eso no se dice así me dice, así, así correcto, muy bueno... Todo vecino muy bueno, nada problema, más bien muy bueno, muy bueno, aja y me ayuda, le primero hija cómo chinea, le cuidar la bebé y todo. (Cheang Chan, 2016, p. 3)

Algunos de los descendientes manifestaron que su familia había vendido todo lo que poseían en Puntarenas para regresar a China. Estuvieron un tiempo en China y luego regresaron perdiendo todas las propiedades que habían adquirido en ese país, debido a la crisis política y económica que se vivía en ese país (Ayí Con, 2016), (Con Wong, 2016).

... después de un tiempo toda la familia, todos se reunieron toda la familia de los Con con nosotros, entonces Isidro Con, José Con todos... se pusieron de acuerdo en volver a China en el 48 creo... en 1948... Estuvieron allá un tiempo no sé cuánto tiempo... Después todos nos devolvimos. (Ayí Con, 2016, p. 1)

Otros descendientes que fueron enviados a estudiar a la China, igualmente regresaron por los problemas políticos y económicos de ese país.

Al final la mayoría se quedaron en Puntarenas y algunos se trasladaron a vivir a la Meseta Central de Costa Rica.

\section{Conclusiones}

Del análisis de los relatos se puede concluir:

- El trabajo duro de los padres inmigrantes que hacía que empleadas tuvieran que cuidar a sus hijos, produjo la pérdida del idioma. Pero también el ingreso a la edad escolar y a relacionarse con los niños de la comunidad hizo que se perdiera en los

\section{(c) (i) (-)}

La Revista Estudios es editada por la Universidad de Costa Rica y se distribuye bajo una Licencia Creative Commons Atribución-NoComercial-CompartirIgual 3.0 Costa Rica. Para más información envíe un mensaje a revistaestudios.eeg@ucr.ac.cr. 
Revista Estudios, (36), 2018.

ISSN 1659-3316

Junio 2018-Noviembre 2018

Chen Mok Susan

hijos la importancia de mantener el idioma. Los descendientes que hablan chino son aquellos cuyos padres les hablaron en chino en sus hogares o tuvieron la oportunidad de estudiar en china.

-Todos los padres de los descendientes entrevistados se dedicaron exitosamente al comercio. Algunos tuvieron industrias, fincas ganaderas o de agricultura. Sus descendientes algunos son comerciantes y los que estudiaron se insertaron en el mercado laboral privado y/o público.

- En la época (mediados del siglo XX) había una necesidad de las familias chinas de enviar a sus hijos a China, sobre todo a los varones, a que aprendieran el idioma chino y sus costumbres.

- La oportunidad de trabajo y mejor vida hicieron que los inmigrantes se quedaran en Costa Rica.

- No hay quejas del trato de los vecinos, los vecinos eran amables y les ayudaron en su adaptación a la sociedad porteña. Las agresiones verbales eran soportables y las ignoraban.

- Los inmigrantes y sus descendientes tenían relaciones de amistad con compañeros y vecinos costarricenses.

- La Asociación China les permitió integrarse a la comunidad, así como mantener y preservar su propia cultura, era un espacio para la recreación y socialización. La Asociación China también era un grupo que ayudaba económicamente a los inmigrantes para que se asentaran e independizaran.

- Los inmigrantes han adaptado su gastronomía con los alimentos que se ofrece en el Puerto, logrando una gastronomía propia que combina ingredientes locales con productos alimenticios chinos.

- La formación de una familia, así como el respeto a los adultos mayores es un rasgo muy importante de los inmigrantes y descendientes de chinos. Además, era posible la convivencia de varias familias en un mismo hogar.

- Los inmigrantes preferían que sus hijos se casaran con inmigrantes chinas, sin embargo, esto no era obligatorio, por lo que varios de los descendientes

\section{(c) (i) (2) (2)}

La Revista Estudios es editada por la Universidad de Costa Rica y se distribuye bajo una Licencia Creative Commons Atribución-NoComercial-CompartirIgual 3.0 Costa Rica. Para más información envíe un mensaje a revistaestudios.eeg@ucr.ac.cr. 
Revista Estudios, (36), 2018.

ISSN 1659-3316

Junio 2018-Noviembre 2018

Chen Mok Susan

contrajeron matrimonio con mujeres u hombres de origen costarricense. También varios de los descendientes trajeron mujeres inmigrantes chinas para contraer matrimonio en Costa Rica o fueron a buscar esposa y casarse en China.

- Los padres inmigrantes ayudaban a otros familiares para que vinieran a Costa Rica y lograran su estabilidad económica y familiar.

- Los padres inmigrantes trabajaban mucho, y los hijos disfrutaban más del tiempo de ocio con sus amigos (iban a bailes, fiestas, paseos), aunque también ayudaban a sus padres en el negocio u oficios domésticos.

Un estudio posterior podría centrarse en los relatos de vida de personas inmigrantes más recientes y más jóvenes, de finales del siglo XX y principios del $X X I$, para conocer semejanzas y diferencias en este proceso y su inserción social con respecto a los inmigrantes del principio y mitad del siglo $\mathrm{XX}$, así como conocer si ha habido cambios en los rasgos culturales con respecto a los del siglo anterior. También sería interesante extender el estudio a otras regiones del país para realizar comparaciones de las mismas variables analizadas.

Otra línea de investigación podría centrarse en el estudio de los aportes a la cultura, a la economía, a la salud, al arte, en general a las diferentes disciplinas, que han dado, los descendientes de los inmigrantes chinos, al país.

Por otro lado, sería interesante realizar un estudio de genealogía, para conocer las relaciones de parentesco que existen entre la población china del país y sus orígenes ancestrales, así como la mezcla en los descendientes que ha diluido los rasgos chinos en la población costarricense, para conocer la cantidad de población que tiene ascendencia china.

\section{(c) (i) (9) (2)}

La Revista Estudios es editada por la Universidad de Costa Rica y se distribuye bajo una Licencia Creative Commons Atribución-NoComercial-CompartirIgual 3.0 Costa Rica. Para más información envíe un mensaje a 


\section{Trabajos citados}

Acón León, A. (16 de 9 de 2016). Relato de vida. (S. Chen, Entrevistador)

Puntarenas, Puntarenas, Costa Rica.

Acón, L. S. (2016). Historia de la Montaña de Oro. San José, Costa Rica.

Alán Sánchez, A. (8 de 4 de 2016). Relato de vida. (S. Chen, Entrevistador) Tres Ríos, San José, Costa Rica.

Apuy Soto, G. (7 de 6 de 2016). Relato de vida. (S. Chen, Entrevistador)

Puntarenas, Puntarenas, Costa Rica.

Asamblea Legislativa. (15 de Noviembre de 1999). Ley Integral para la Persona Adulta Mayor. La Gaceta No.221, Alcance No.88. San José, Costa Rica.

Ayí Con, J. (5 de 9 de 2016). Relato de vida. (S. Chen, Entrevistador) Uruca, San José, Costa Rica.

Bertaux, D. (2005). Los relatos de vida. Barcelona, España: Ediciones Bellaerra, S.L.

Chan Golfín, R. (9 de 9 de 2016). Relato de vida. (S. Chen, Entrevistador) El Roble, Puntarenas, Costa Rica.

Chan Li, J. (6 de 5 de 2016). Relato de vida. (S. Chen, Entrevistador) El Roble, Puntarenas, Costa Rica.

Chango Achio, F. (1 de 3 de 2016). Relato de vida. (S. Chen, Entrevistador) Barranca, Puntarenas, Costa Rica.

Cheang Chan, M. (12 de 9 de 2016). Relato de vida. (S. Chen, Entrevistador) Tres Ríos, San José, Costa Rica.

Chen, S. (2016a). Proyecto Recuperación de la memoria fotográfica y relatos de vida de los inmigrantes chinos de la ciudad de Puntarenas, siglo XX. Universidad de Costa Rica, Sede del Pacífico, Puntarenas.

Chen, S. (2016b). Base de Datos Fotográfica Proyecto Recuperación de la Memoria Fotográfica y Relatos de Vida de los Inmigrantes Chinos y descendientes de Puntarenas: Siglo XX. UCR. Puntarenas, Costa Rica.

Chin Fong, R. (8 de 8 de 2016). Relato de vida. (S. Chen, Entrevistador) Pavas, San José, Costa Rica.

\section{(c) (i) (2)}

La Revista Estudios es editada por la Universidad de Costa Rica y se distribuye bajo una Licencia Creative Commons Atribución-NoComercial-Compartirlgual 3.0 Costa Rica. Para más información envíe un mensaje a 
Revista Estudios, (36), 2018.

Con Wong, I. (19 de 5 de 2016). Relato de vida. (S. Chen, Entrevistador) San José, Costa Rica.

Li Chen, A. (22 de 1 de 2016). Relato de vida. (S. Chen, Entrevistador)

Li Cheng, C. L. (10 de 3 de 2016). Relato de vida. (S. Chen, Entrevistador) Puntarenas, Puntarenas, Costa Rica.

Li Shi, R. (9 de 2 de 2016). Relato de vida. (S. Chen, Entrevistador) Puntarenas, Puntarenas, Costa Rica.

Lo Tsan, S. (1 de 2 de 2016). Relato de vida. (S. Chen, Entrevistador) Puntarenas, Puntarenas, Costa Rica.

Sánchez Chan, M. (26 de 5 de 2016). Relato de vida. (S. Chen, Entrevistador) San José, Costa Rica.

Sui Mok, C. Y. (1 de 10 de 2016). Relato de vida. (S. Chen, Entrevistador) Puntarenas, Puntarenas, Costa Rica.

Wong Chan, F. (20 de 6 de 2016). Relato de vida. (S. Chen, Entrevistador) Puntarenas, Puntarenas, Costa Rica.

Wong Soto, Y. (25 de 1 de 2016). Relato de vida. (S. Chen, Entrevistador) Puntarenas, Puntarenas, Costa Rica. 